\title{
Significance of defect closure following transanal local full-thickness excision of rectal malignant tumors
}

\author{
SHINGO NOURA $^{1,2}$, MASAYUKI OHUE ${ }^{1}$, NORIKATSU MIYOSHI ${ }^{1}$ and MASAYOSHI YASUI ${ }^{1}$ \\ ${ }^{1}$ Department of Surgery, Osaka Medical Center for Cancer and Cardiovascular Diseases, Osaka, Osaka 537-8511; \\ ${ }^{2}$ Department of Surgery, Osaka Rosai Hospital, Sakai, Osaka 591-8025, Japan
}

Received April 12, 2016; Accepted June 27, 2016

DOI: $10.3892 / \mathrm{mco} .2016 .979$

\begin{abstract}
Transanal excision (TAE) for rectal tumors is increasingly applied and it is generally recommended that the defect following full-thickness excision should be closed. The aim of this study was to compare the complications and anal function following TAE between cases where the defect was closed and those where it was not. A total of 43 consecutive rectal malignant tumor patients eligible for TAE were investigated. Regarding anorectal function, incontinence was assessed using the Wexner score. The defect of the rectum was closed in 21 of the 43 patients. There were no significant differences between the two groups regarding gender, distance from the anal verge, tumor size, diagnosis and tumor site. There was a significantly higher number of postoperative complications of all grades and $\geq$ Clavien-Dindo grade IIIa in the closure group ( $\mathrm{P}=0.02$ and 0.04 , respectively). Regarding the Wexner score, there was no significant difference between the two groups $(\mathrm{P}=0.24)$. Compared with the closure group, the non-closure group had significantly fewer postoperative complications of all grades and $\geq$ Clavien-Dindo grade IIIa. Moreover, there was no significant difference regarding the anorectal function between the two groups. Thus, suturing the rectal defect is not necessarily recommended following TAE.
\end{abstract}

\section{Introduction}

Although advances in rectal surgery have broadened the choice of sphincter-preserving procedures, definitive colostomy remains necessary in $10-30 \%$ of the patients (1). Furthermore, the postoperative morbidity and mortality rates remain high (2). In addition to urinary dysfunction, disturbances in bowel function prove to be a major problem in $\sim 30 \%$ of the patients $(3,4)$.

Correspondence to: Dr Shingo Noura, Department of Surgery, Osaka Rosai Hospital, 1179-3 Nagasone-cho, Sakai, Osaka 591-8025, Japan

E-mail: s-noura@orh.go.jp

Key words: transanal excision, transanal minimally invasive surgery, rectal tumor, full-thickness excision, morbidity
Benign and early-stage malignant tumors located in the lower rectum have been traditionally managed with local excision (LE) using a conventional instrument, such as the Parks anal retractor, which has also become valuable for selecting patients with a rectal malignant tumor. However, this approach has major limitations, as exposure and visibility within the rectal lumen curtail the surgeon's ability to perform a high-quality oncological excision. Since the introduction of transanal endoscopic microsurgery (TEM), which was first described by Buess et al (5), TEM has become the treatment of choice for benign and early-stage malignant tumors that are not suitable for LE with the Parks anal retractor or a flexible endoscope $(6,7)$. However, several factors have limited the widespread application of TEM, including the need for specialized expensive instruments and a steep learning curve (8). To overcome these restrictions, transanal minimally invasive surgery (TAMIS) has recently become more accessible to general surgeons through the use of single-port access systems and usual laparoscopic instruments. TAMIS with SILS ${ }^{\text {TM }}$ Port (Coviden, Mansfield, MA, USA), a novel approach combining TEM and single-port laparoscopic surgery, was first reported in 2010 by Atallah (9). Recently, a systematic review of TAMIS was reported (10). In this study, LE was defined as excision with a retractor (such as the Parks anal retractor) and TAMIS was defined as excision with a single-incision laparoscopic surgery port [such as the GelPOINT ${ }^{\circledR}$ path platform (Applied Medical, Rancho Santa Margarita, CA, USA) or SILS ${ }^{\mathrm{TM}}$ Port]. TAE included both LE and TAMIS.

The major advantages of TAE are the significantly lower morbidity and better functional outcome compared with standard radical resection $(11,12)$. The reported complications include postoperative bleeding necessitating reoperation, wound dehiscence, bladder dysfunction and wound infection (13). Surgical emphysema following TAE is extremely rare $(14,15)$.

When TAE was performed, the biggest challenge encountered was the decision on whether to close the defect. Although several authors have recommended suturing on the basis of earlier wound healing, better bleeding control and fewer cases of lumen stenosis (16-18), some authors have advocated that the defect should not always be closed $(19,20)$.

The aim of this study was to compare the complications and anal function following TAE of rectal tumors between cases where the defect was closed and those where it was not, through a retrospective investigation. 


\section{Patients and methods}

Patients. Between January, 2004 and March, 2015, 43 consecutive rectal malignant tumor patients eligible for TAE were investigated. The patients were clinically diagnosed prior to surgery according to the findings of colonoscopy and computed tomography and they had no metastasis in the regional lymph nodes or distant metastases on preoperative diagnosis. A digital examination was the most important assessment. Each digital examination was inevitably performed preoperatively in all patients to determine the location, size and depth of the tumor. None of the patients received preoperative chemotherapy or radiotherapy.

Operation. At the Osaka Medical Center for Cancer and Cardiovascular Diseases (Osaka, Japan) our hospital, the indications for TAE for rectal malignant tumors are a maximum diameter of $3 \mathrm{~cm}$, clinically $\mathrm{T} 1$ or T2 depth and the absence of lymph node and distant metastasis. The tumors were located below the peritoneal reflection. Mechanical bowel preparation was performed preoperatively, in the same manner as in usual conventional colorectal surgery, and intravenous antibiotics were administered perioperatively in all cases. Preoperative chemical preparation with antibiotics was not performed. In all patients, TAE with full-thickness excision was performed under general or spinal anesthesia. Regarding the operative procedure, LE with the Parks anal retractor was performed in 35 and TAMIS with the GelPOINT ${ }^{\circledR}$ Path in 8 patients, although GelPOINT ${ }^{\circledR}$ Path is currently used in the majority of the patients in our hospital. Following complete removal of the lesion, the decision on defect closure relied upon the operator's assessment.

Postoperative management. General postoperative management was as follows: The patients received intravenous fluids and antibiotics until the morning of postoperative day (POD) 1. Water ingestion was initiated on POD 1 and solid food consumption on POD 2.

Anorectal function. Fecal incontinence was assessed using the continence score of Jorge and Wexner (Wexner score) (21) at 3 , 6, 9 and 12 months after the operation. Questionnaires were obtained when patients visited the hospital.

Statistical analysis. A statistical analysis was performed using the SPSS software program for Windows, version 21 (IBM SPSS, Armonk, NY, USA). Associations between the clinicopathological parameters were assessed using the Chi-square test or the Fisher's exact test for discrete variables. The Student's t-test was used for continuous variables. P-values of $<0.05$ were considered to indicate statistically significant differences.

\section{Results}

Patient characteristics. In 21 of the 43 patients (48.8\%), the defect of the rectum was closed. As shown in Table I, a comparison of the patients with and without closure revealed no significant differences between the two groups regarding gender, distance from the anal verge, tumor size, diagnosis and tumor site. Regarding the age and operative procedure, a significant difference was observed between the two groups $(\mathrm{P}=0.04$ and 0.004 , respectively).

Results of the operation. The details of the operation are shown in Table II. Overall, the mean operative time was $72.5 \mathrm{~min}$ (range, 15-220 min; median, $65 \mathrm{~min}$ ), with the operation completed within $90 \mathrm{~min}$ in $\sim 80 \%$ of the cases. In our study, closure of the defect did not affect the operative time. The mean intraoperative blood loss was $51.5 \mathrm{ml}(61.7 \mathrm{ml}$ in the closure and $41.8 \mathrm{ml}$ in the non-closure group). Although the amount of blood loss in the closure group appeared to be higher, there was no statistically significant difference between the two groups. The mean postoperative hospital stay of the closure group was longer compared with that of the non-closure group, but the difference was not statistically significant $(\mathrm{P}=0.32)$.

Regarding the anterior, posterior and lateral tumor localization, there was no statistically significant difference in operative time. However, the amount of blood loss from anteriorly located tumors was lower compared with that in other sites (anterior vs. posterior: 13 vs. $61 \mathrm{ml}$, respectively, $\mathrm{P}=0.03$; and anterior vs. lateral: 13 vs. $87 \mathrm{ml}$, respectively, $\mathrm{P}=0.05$ ).

The operative procedure was also investigated. As regards the mean operative time, there was no statistically significant difference between the two groups (70.0 min in LE with the Parks anal retractor and $83.3 \mathrm{~min}$ in TAMIS with GelPOINT ${ }^{\circledR}$ Path; $\mathrm{P}=0.43$ ). Furthermore, there was a lower amount of blood loss in TAMIS with the GelPOINT ${ }^{\circledR}$ Path compared with LE with the Parks anal retractor (5.0 vs. $62.1 \mathrm{ml}$, respectively); however, this difference was not statistically significant $(\mathrm{P}=0.09)$.

Postoperative pathology and additional therapy. Postoperative pathology (Table III) confirmed the presence of adenocarcinoma in 41 patients and carcinoid in 2 patients. Of the 41 adenocarcinoma patients, the histopathological findings showed G1 (well-differentiated) in 23, G2 (moderately differentiated) in 16, and G3 (poorly differentiated) in 2 patients. The depth of the tumor was as follows: Tis cancer in 1, T1 cancer in 26, T2 cancer in 12 and T3 cancer in 2 patients.

En bloc resection was generally attempted; however, fragmentation of the specimen occurred in $5(11.6 \%)$ of the 43 patients. The horizontal margin was negative in all 43 patients $(100 \%)$; however, the vertical margin was positive in $3(7.0 \%)$ of the 43 patients. Due to a positive vertical margin $(n=3)$ or local recurrence $(n=1)$, additional bowel resection with lymphadenectomy was performed in 4 cases. Therefore, 39 cases successfully underwent surgical therapy with TAE alone. However, according to the results of the pathological examination, adjuvant chemotherapy was performed in 1 and adjuvant chemoradiotherapy (CRT) in 27 patients.

Postoperative complications and anorectal function. There were no reported deaths in this study. The overall morbidity rate was $18.6 \%$ ( 8 of the 43 patients) (Table IV). In the overall cohort, the most common complications were postoperative bleeding $(11.6 \%$; $n=5)$, followed by fever $(2.3 \%$; $=1)$, anal pain $(2.3 \% ; n=1)$ and retroperitoneal emphysema $(2.3 \% ; n=1)$. In the closure group, 5 patients $(23.8 \%)$ experienced postoperative bleeding, and 1 patient did not require any special treatment 
Table I. Patient characteristics.

\begin{tabular}{|c|c|c|c|}
\hline Characteristics & Closure $(n=21)$ & No closure $(n=22)$ & P-value \\
\hline Age (years) & $59.6 \pm 8.6(44-76)$ & $64.7 \pm 7.8(48-79)$ & 0.04 \\
\hline \multicolumn{4}{|l|}{ Gender } \\
\hline Male & 11 & 11 & $>0.99$ \\
\hline Female & 10 & 11 & 10 \\
\hline Distance from the anal verge $(\mathrm{cm})$ & $4.3 \pm 1.6(2.0-7.0)$ & $4.5 \pm 1.8(2.0-7.5)$ & 0.75 \\
\hline Tumor size $(\mathrm{cm})$ & $2.2 \pm 0.8(1.0-3.0)$ & $2.6 \pm 1.2(1.5-3.0)$ & 0.37 \\
\hline Diagnosis & & & 0.23 \\
\hline Adenocarcinoma & 19 & 22 & \\
\hline Carcinoid & 2 & 0 & \\
\hline Operative procedure & & & 0.004 \\
\hline Parks anal retractor & 21 & 14 & \\
\hline GelPOINT $^{\circledR}$ path & 0 & 8 & \\
\hline Tumor site & & & 0.69 \\
\hline Anterior & 8 & 6 & \\
\hline Posterior & 8 & 11 & \\
\hline Lateral & 5 & 5 & \\
\hline
\end{tabular}

Data are expressed as the mean \pm standard deviation (range) or absolute numbers.

Table II. Results of the operation.

\begin{tabular}{llll}
\hline Variables & Closure $(\mathrm{n}=21)$ & No closure $(\mathrm{n}=22)$ & P-value \\
\hline Operative time (min) & $72.5 \pm 51.9(15-220)$ & $72.6 \pm 34.0(23-152)$ & 0.99 \\
Blood loss (ml) & $61.7 \pm 97.5(5-330)$ & $41.8 \pm 73.2(5-300)$ & 0.45 \\
Postoperative hospital stay (days) & $12.6 \pm 11.5(5-58)$ & $9.9 \pm 4.9(5-19)$ & 0.32 \\
\hline
\end{tabular}

Data are expressed as mean \pm standard deviation (range).

(Clavien-Dindo grade I). However, the remaining 4 patients required blood transfusion (grade II; n=1) and endoscopic hemostatic therapy (grade IIIa; $n=3$ ). No postoperative bleeding occurred in the non-closure group. The difference between the two groups was statistically significant $(\mathrm{P}=0.02)$. In the closure group, fever developed in 1 patient (4.8\%), but no special treatment was required (grade II). In the non-closure group, anal pain was experienced by 1 patient $(4.8 \%)$, but no special treatment was required (grade II). One patient $(4.8 \%)$ in the closure group developed retroperitoneal emphysema and loop colostomy was performed (grade IIIb). There was no significant difference in the incidence of the aforementioned complications between the two groups $(\mathrm{P}=0.49,0.99$ and 0.49 , respectively). There were no cases with urinary dysfunction or rectal stricture in any of the two groups.

Overall, complications occurred in $18.6 \%$ (8/43) of the patients. There was a significant difference between the two groups [closure vs. non-closure: $33.3 \%$ (7/21) vs. $4.5 \%(1 / 22)$; $\mathrm{P}=0.02]$. In particular, severe complications ( $\geq$ grade IIIa) occurred in $9.3 \%$ (4/43) of the patients, with a statistically significant difference between the two groups [closure vs. non-closure: $19.0 \%(4 / 21)$ vs. $0 \%(0 / 22)$; $\mathrm{P}=0.04]$.
Table III. Postoperative pathology.

\begin{tabular}{lc}
\hline Variables & Patients (n=43) \\
\hline Histological diagnosis & 23 \\
Adenocarcinoma & 16 \\
G1 (well-differentiated) & 2 \\
G2 (moderately differentiated) & 2 \\
G3 (poorly differentiated) & \\
Carcinoid & 1 \\
Depth of the tumor (adenocarcinoma) & 26 \\
Tis & 12 \\
T1 & 2 \\
T2 & $5(11.6 \%)$ \\
T3 & $43(100 \%)$ \\
Fragmentation of the specimen & $40(93.0 \%)$ \\
Horizontal margin negative $(\%)$ & \\
Vertical margin negative (\%)
\end{tabular}

Data are expressed as number (percentage). 
Table IV. Postoperative complications.

\begin{tabular}{|c|c|c|c|c|}
\hline Complications & Total $(n=43)$ & Closure $(n=21)$ & No closure $(n=22)$ & P-value \\
\hline Bleeding & $5(11.6 \%)$ & $5(23.8 \%)$ & $0(0 \%)$ & 0.02 \\
\hline Fever & $1(2.3 \%)$ & $1(4.8 \%)$ & $0(0 \%)$ & 0.49 \\
\hline Anal pain & $1(2.3 \%)$ & $0(0 \%)$ & $1(4.5 \%)$ & 0.99 \\
\hline Retroperitoneal emphysema & $1(2.3 \%)$ & $1(4.8 \%)$ & $0(0 \%)$ & 0.49 \\
\hline All grades & $8(18.6 \%)$ & $7(33.3 \%)$ & $1(4.5 \%)$ & 0.02 \\
\hline$\geq$ Clavien-Dindo grade IIIa & $4(9.3 \%)$ & $4(19.0 \%)$ & $0(0 \%)$ & 0.04 \\
\hline
\end{tabular}

Data are expressed as number (percentage).

Table V. Wexner score in patients with TAE.

\begin{tabular}{|c|c|c|c|c|}
\hline Timepoint & Total $(n=27)$ & Closure $(n=16)$ & No closure $(n=11)$ & P-value \\
\hline 3 months $(n=27)$ & $0.74 \pm 1.40(0-5)$ & $0.31 \pm 0.60(0-2)$ & $1.36 \pm 1.96(0-5)$ & 0.05 \\
\hline 6 months $(n=27)$ & $0.37 \pm 0.93(0-3)$ & $0.13 \pm 0.56(0-2)$ & $0.73 \pm 1.27(0-3)$ & 0.09 \\
\hline 9 months $(n=27)$ & $0.23 \pm 0.65(0-2)$ & $0.13 \pm 0.50(0-2)$ & $0.40 \pm 0.84(0-2)$ & 0.30 \\
\hline 12 months $(\mathrm{n}=27)$ & $0.08 \pm 0.39(0-2)$ & 0 & $0.20 \pm 0.63(0-2)$ & 0.21 \\
\hline
\end{tabular}

Data are expressed as mean \pm standard deviation (range). TAE, transanal excision.

Of the 39 patients who underwent TAE alone, 27 were available for follow-up (follow-up period $\geq 12$ months). To evaluate the Wexner score, questionnaires were obtained from the 27 patients at 3, 6, 9 and 12 months (Table V). CRT was administered to 11 patients in the closure group $(n=16)$ and 8 patients in the non-closure group $(n=11)$. No significant difference between the two groups was observed $(\mathrm{P}=0.99)$. In all cases, an improvement was observed from 3 to 6 months $(\mathrm{P}=0.009)$. A gradual improvement was observed from 6 to 9 or 12 months; however, the improvement was not significant. A comparison between the closure and non-closure groups revealed a significant difference at 12 months (closure vs. non-closure: 0.00 vs. 0.20 , respectively; $\mathrm{P}=0.21$ ). Regarding the effect of radiation therapy on anorectal function, there was no statistically significant difference between the two groups at 12 months (CRT vs. no CRT: 0.11 vs. 0.00 , respectively; $\mathrm{P}=0.52$ ).

\section{Discussion}

The approach of local excision for tumors of the rectum was introduced in 1826 by Lisfranc (22). Subsequently, transanal techniques, such as the Parks excision (23), have progressed. Following the introduction of TEM into clinical practice (5), it has progressively become the standard for the treatment of benign polyps and early neoplasms in the extraperitoneal rectum $(6,7)$. Widespread application of TEM, however, has progressed slowly, in part because the surgeon is forced to work through a long rigid rectoscope, which limits triangulation and subsequent instrument manipulation. To overcome these restrictions, TAMIS using the SILS ${ }^{\mathrm{TM}}$ Port and general laparoscopic instruments was first reported in 2010 by Atallah (9). This was followed by various reports of TAMIS with an increasing number of case reports using similar platforms with acceptable outcomes (10,24-26).

The major advantage of TAE is the significantly lower morbidity and mortality compared with the traditional treatment for rectal malignant tumors, such as abdominoperineal or low anterior resection (27). Postoperative complications are relatively rare and include bleeding (1.7-2.7\%) and pelvic sepsis $(1-2.7 \%)$. The mortality rate is low (0-2\%) (28). In our study, the most frequent complication was postoperative bleeding (62.5\%, 5 of 8 cases). Such complications, particularly postoperative bleeding, may be associated with differences in the operative procedures between the two groups. When the Parks anal retractor was applied, an electric cautery device was commonly used. However, when the GelPOINT path was applied, a vessel-sealing device was used. In the closure group, all patients were operated on with the Parks anal retractor. However, in the non-closure group, $\sim 40 \%$ of the patients were operated on with the GelPOINT path. In the closure group, the complication rate was higher compared with that in the non-closure group. The use of a vessel-sealing device may therefore reduce postoperative bleeding. Very rare complications include surgical emphysema $(14,15)$. In the closure group, 1 case developed extended retroperitoneal emphysema and underwent emergent colostomy. According to Bignell et al (28), pelvic sepsis often occurs in patients with a tumor located within $2 \mathrm{~cm}$ from the dentate line $(6.5 \mathrm{vs} .0 .5 \%$, respectively; $\mathrm{P}<0.02$ ), due to the absence of mesorectum in the distal rectum. The tumor location of our retroperitoneal emphysema case was $2 \mathrm{~cm}$ from the dentate line. With the increasing use of TAE, we should take note of this complication. The wound dehiscence rate after full-thickness excision is not negligible and it ranges from 1 to $20.9 \%$ (29-31). We 
hypothesized that, if the defect is closed and wound dehiscence subsequently occurs, then the wound may split deeply. As a result, the rectal air escapes to the retroperitoneum or pelvic cavity, or postoperative bleeding occurs from the split wound. In our study, no pelvic sepsis or bleeding was observed in the non-closure group.

Furthermore, TAE has a major advantage over general open or laparoscopic surgery regarding anorectal function. If abdominoperineal resection is performed, permanent colostomy is necessary. Although low anterior resection or intersphincteric resection (ISR) preserving the anus are performed, the patients often present with frequent defecation or fecal incontinence. The Wexner score at 1 year after the operation is reportedly poor (4.4-10.0) (32,33). In our study, the Wexner score at 12 months after the operation was good (0.08). Generally, the anorectal function becomes worse following pre- or postoperative CRT $(32,34)$. However, in our study, no significant difference in the effect of radiation therapy was observed at 12 months. We hypothesized that the good anorectal function observed may be attributed to the preservation of most of the internal sphincter, unlike ISR in TAE.

To perform TAE, the most critical issue is suturing (35). When TAE is performed, one of the last decisions to be made during the operation is whether to close the defect. Although most groups recommended suturing the defect (16-18), some have advocated that the defect should not always be closed (19,20). Ramirez et al (19) reported difficulties in repairing the excision defect and concluded that there was no difference between whether the defect was sutured or not regarding the intraoperative results and outcome. At 4 weeks after the operation, the rectal wound had completely healed in $84 \%$ of the patients in the unsutured group and $95 \%$ of the patients in the sutured group. Hahnloser et al (20) reported there was no difference in the incidence of complications whether the rectal defect was closed or left open. There remains no consensus or guidance among TEM surgeons regarding the closure of a defect below the peritoneal reflection; thus far, no distinct differences have been reported regarding postoperative complications based on whether the defect had been closed or not (28). In our study, postoperative severe complications ( $\geq$ grade IIIa) occurred in 4 cases in the closure group. There were no complications in the non-closure group. Regarding anorectal function, even if the defect was left open, continence was not compromised at 1 year after surgery (20). In our study, similarly, there was no significant difference in the Wexner score between the two groups at 12 months.

In conclusion, although our study included a limited number of cases and was not a randomized controlled trial, a significant difference was observed in postoperative complications of all grades between the closure and non-closure groups (33.3 vs. $4.5 \%$, respectively; $\mathrm{P}=0.02$ ) and $\geq$ grade IIIa (19.0 vs. $0 \%$, respectively; $\mathrm{P}=0.04)$. Moreover, there was no significant difference regarding anorectal function between the two groups. Thus, suturing the defect following TAE is not necessarily recommended.

\section{Acknowledgements}

The present study was supported in part by the Public Trust Surgery Research Fund.

\section{References}

1. Morris E, Quirke P, Thomas JD, Fairley L, Cottier B and Forman D: Unacceptable variation in abdominoperineal excision rates for rectal cancer: Time to intervene? Gut 57: 1690-1697, 2008.

2. Morino M, Parini U, Giraudo G, Salval M, Brachet Contul R and Garrone C: Laparoscopic total mesorectal excision: A consecutive series of 100 patients. Ann Surg 237: 335-342, 2003.

3. Ho P, Law WL, Chan SC, Lam CK and Chu KW: Functional outcome following low anterior resection with total mesorectal excision in the elderly. Int J Colorectal Dis 18: 230-233, 2003.

4. Wallner C, Lange MM, Bonsing BA, Maas CP, Wallace CN, Dabhoiwala NF, Rutten HJ, Lamers WH, Deruiter MC and van de Velde CJ; Cooperative Clinical Investigators of the Dutch Total Mesorectal Excision Trial: Causes of fecal and urinary incontinence after total mesorectal excision for rectal cancer based on cadaveric surgery: A study from the cooperative clinical investigators of the Dutch total mesorectal excision trial. J Clin Oncol 26: 4466-4472, 2008.

5. Buess G, Theiss R, Günther M, Hutterer F and Pichlmaier H: Endoscopic surgery in the rectum. Endoscopy 17: 31-35, 1985.

6. Moore JS, Cataldo PA, Osler T and Hyman NH: Transanal endoscopic microsurgery is more effective than traditional transanal excision for resection of rectal masses. Dis Colon Rectum 51: 1026-1030; discussion 1030-1031, 2008.

7. Casadesus D: Surgical resection of rectal adenoma: A rapid review. World J Gastroenterol 15: 3851-3854, 2009.

8. Middleton PF, Sutherland LM and Maddern GJ: Transanal endoscopic microsurgery: A systematic review. Dis Colon Rectum 48: 270-284, 2005

9. Atallah S, Albert M and Larach S: Transanal minimally invasive surgery: A giant leap forward. Surg Endosc 24: 2200-2205, 2010.

10. Martin-Perez B, Andrade-Ribeiro GD, Hunter L and Atallah S: A systematic review of transanal minimally invasive surgery (TAMIS) from 2010 to 2013. Tech Coloproctol 18: 775-788, 2014.

11. Bach SP, Hill J, Monson JR, Simson JN, Lane L, Merrie A, Warren B and Mortensen NJ; Association of Coloproctology of Great Britain and Ireland Transanal Endoscopic Microsurgery (TEM) Collaboration: A predictive model for local recurrence after transanal endoscopic microsurgery for rectal cancer. $\mathrm{Br} \mathrm{J}$ Surg 96: 280-290, 2009.

12. Doornebosch PG, Tollenaar RA, Gosselink MP, Stassen LP, Dijkhuis CM, Schouten WR, van de Velde CJ and de Graaf EJ: Quality of life after transanal endoscopic microsurgery and total mesorectal excision in early rectal cancer. Colorectal Dis 9: 553-558, 2007.

13. Gall FP and Hermanek P: Cancer of the rectum-local excision. Surg Clin North Am 68: 1353-1365, 1988.

14. Franken RJ, Moes DE, Acherman YI and Derksen EJ: Free Intra-abdominal air without peritoneal perforation after TEM: A report of two cases. Case Rep Surg 2012: 185429, 2012.

15. Simkens GA, Nienhuijs SW, Luyer MD and de Hingh IH: Massive surgical emphysema following transanal endoscopic microsurgery. World J Gastrointest Surg 6: 160-163, 2014.

16. Bleday R: Local excision of rectal cancer. World J Surg 21: 706-714, 1997.

17. Lawrence MA and Goldberg SM: Local excision for selected colorectal carcinomas. Baillieres Clin Gastroenterol 3: 727-737, 1989.

18. Buess G, Mentges B, Manncke K, Starlinger M and Becker HD: Technique and results of transanal endoscopic microsurgery in early rectal cancer. Am J Surg 163: 63-69; discussion 69-70, 1992.

19. Ramirez JM, Aguilella V, Arribas D and Martinez M: Transanal full-thickness excision of rectal tumours: Should the defect be sutured? a randomized controlled trial. Colorectal Dis 4: 51-55, 2002.

20. Hahnloser D, Cantero R, Salgado G, Dindo D, Rega D and Delrio P: Transanal minimal invasive surgery for rectal lesions: Should the defect be closed? Colorectal Dis 17: 397-402, 2015.

21. Jorge JM and Wexner SD: Etiology and management of fecal incontinence. Dis Colon Rectum 36: 77-97, 1993.

22. No authors listed: Classic articles in colonic and rectal surgery. Jacques Lisfranc 1790-1847. Observation on a cancerous condition of the rectum treated by excision. Dis Colon Rectum 26: 694-695, 1983.

23. Parks AG: A technique for excising extensive villous papillomatous change in the lower rectum. Proc R Soc Med 61: 441-442, 1968. 
24. Lim SB, Seo SI, Lee JL, Kwak JY, Jang TY, Kim CW, Yoon YS, Yu CS and Kim JC: Feasibility of transanal minimally invasive surgery for mid-rectal lesions. Surg Endosc 26: 3127-3132, 2012.

25. Hayashi S, Takayama T, Yamagata M, Matsuda M and Masuda H Single-incision laparoscopic surgery used to perform transana endoscopic microsurgery (SILSTEM) for T1 rectal cancer under spinal anesthesia: Report of a case. Surg Today 43: 325-328, 2013.

26. Albert MR, Atallah SB, deBeche-Adams TC, Izfar S and Larach SW: Transanal minimally invasive surgery (TAMIS) for local excision of benign neoplasms and early-stage rectal cancer: Efficacy and outcomes in the first 50 patients. Dis Colon Rectum 56: 301-307, 2013.

27. Leonard D, Remue C and Kartheuser A: The transanal endoscopic microsurgery procedure: Standards and extended indications Dig Dis 30 (Suppl 2): S85-S90, 2012.

28. Bignell MB, Ramwell A, Evans JR, Dastur N and Simson JN: Complications of transanal endoscopic microsurgery (TEMS): A prospective audit. Colorectal Dis 12: e99-e103, 2010.

29. Ganai S, Kanumuri P, Rao RS and Alexander AI: Local recurrence after transanal endoscopic microsurgery for rectal polyps and early cancers. Ann Surg Oncol 13: 547-556, 2006.

30. Allaix ME, Arezzo A, Cassoni P, Famiglietti F and Morino M: Recurrence after transanal endoscopic microsurgery for large rectal adenomas. Surg Endosc 26: 2594-2600, 2012.
31. Marks JH, Marchionni C and Marks GJ: Transanal endoscopic microsurgery in the treatment of select rectal cancers or tumors suspicious for cancer. Surg Endosc 17: 1114-1117, 2003.

32. Ito M, Saito N, Sugito M, Kobayashi A, Nishizawa Y and Tsunoda Y: Analysis of clinical factors associated with anal function after intersphincteric resection for very low rectal cancer. Dis Colon Rectum 52: 64-70, 2009.

33. Kakodkar R, Gupta S and Nundy S: Low anterior resection with total mesorectal excision for rectal cancer: Functional assessment and factors affecting outcome. Colorectal Dis 8: 650-656, 2006.

34. Kollmorgen CF, Meagher AP, Wolff BG, Pemberton JH, Martenson JA and Illstrup DM: The long-term effect of adjuvant postoperative chemoradiotherapy for rectal carcinoma on bowel function. Ann Surg 220: 676-682, 1994.

35. Rimonda R, Arezzo A, Arolfo S, Salvai A and Morino M: TransAnal minimally invasive surgery (TAMIS) with SILS ${ }^{\mathrm{TM}}$ port versus transanal endoscopic microsurgery (TEM): A comparative experimental study. Surg Endosc 27: 3762-3768, 2013. 